\title{
EDITORIAL
}

\section{TRANSFERÊNCIAS CULTURAIS}

Em meados da década de 1980, na França e na área franco-alemã, se desenvolveu a noção de transferência cultural, enfatizando a complexidade dos processos de deslocamento, particularmente no campo dos estudos literários e históricos. Essa noção exclui qualquer empobrecimento do conteúdo inicial na passagem de um objeto cultural de um contexto para outro e exige a intersecção de abordagens hermenêuticas e sociológicas na circulação de obras, teorias e livros. O termo "transferência cultural" traz à tona a ideia de circulação, de passagem, um ir e vir que integra múltiplos fenômenos como intertextualidade, tradução, reescrita, etc. sem privilegiar o ponto de partida, questionando a categoria de influência, que pressupõe a ascendência de uma cultura sobre outra e uma espécie de hierarquia, mas insistindo na dinâmica da ressemantização. Acima de tudo, o estudo das transferências culturais não visa comparar culturas, mas seguir os detalhes do entrelaçamento e das interações que as constituem. Compreender uma transferência cultural envolve frequentemente prestar atenção à história dos livros, bibliotecas, a aquisição de conhecimento, especialmente os linguísticos, e todos os estágios da mediação.

Com o objetivo de contribuir para mapear os estudos atuais, a Revista Jangada propôs um dossiê dedicado às Transferências Culturais, objetivando provocar uma discussão que abordasse o panorama de usos específicos para o conceito, seus objetos culturais e as questões que integram a prática de cada pesquisa, considerando a diversidade e multiplicidade de perspectivas oferecidas pelo tema. Assim, este dossiê busca aprofundar a reflexão sobre as transferências culturais, seja no que diz respeito aos encontros literários e à teoria literária, seja na busca de novos pontos de vista dentro da historiografia cultural. E, parece-nos, cumprimos a contento o que havíamos previsto ao provocarmos professores e pesquisadores a apresentar suas contribuições - algo que o leitor poderá constatar ao perscrutar os trabalhos que compõem o dossiê. 
Dividimos o dossiê em cinco sequências. A primeira, dedicada às relações Brasil-França em seus múltiplos aspectos, valorizando a produção romanesca, lírica e jornalística a partir dos autores abordados. Em "Os ecos da revoluções de 1848 no Brasil: formas de pensamento, literatura política e transferências culturais", o primeiro artigo deste dossiê, Marisa Midori Deaecto analisa, a partir da leitura dos jornais cariocas, não só os debates políticos suscitados no Brasil à época das Revoluções de 1848, mas também o comportamento da imprensa e o parti pris dos formadores de opinião face às Revoluções de 1830 e 1848.

Às portas da comemoração do centenário de desaparecimento de Marcel Proust, Fillipe Mauro traz "Ó mon petit Marcel: quatro poemas brasileiros sobre Proust”, artigo em que o autor parte de um poema de Paul Morand dedicado a Proust, para lançar-se sobre a produção de Augusto Meyer, João Cabral de Melo Neto, Jorge de Lima e Cláudio Murilo Leal, poetas que, cada um a seu modo, "leram" a Recherche estética e intertextualmente, tornando-a parte de suas produções líricas e artísticas. “A 'escola realista' francesa: uma invenção do teatro brasileiro? (Anos 1850-1860)", de Daniel Polleti, volta-se para o teatro de boulevard, gênero "adotado pelos homens de letras brasileiros" nas décadas de 1850 e 1860. O autor discorre sobre como a dramaturgia realista prosperou no Brasil e provocou transformações nas artes e na sociedade, ressignificando processos intelectuais da tradição local. Em "Brasil telegrafado: o impacto das novas tecnologias de informação sobre a circulação de objetos e mediadores culturais entre Brasil e França (1874-1899)", Tanize Costa Monnerat trata das publicações francesas oitocentistas do fim de século e do advento das novas tecnologias (telégrafo e agências de imprensa), as quais provocaram a "ressignificação de antigas práticas jornalísticas e a exploração de novos temas", permitindo o surgimento de uma nova imagem do Brasil. Grace Alves da Paixão, por sua vez, em "Sérgio Buarque de Holanda: encontros literários FrançaBrasil (1920)", se debruça sobre a obra de Buarque de Holanda enquanto crítico ligado às vanguardas modernistas, revelando o olhar de um intelectual inquieto que, dentre outros aspectos, revela uma profunda interconexão com a França, país com o qual mantinha muitas afinidades. E, para encerrar essa sequência dedicada às relações Brasil-França, Yue Qi, com “Mettre la 'Chine contemporaine' à l'épreuve des transferts culturels franco-brésiliens: le cas de Mon Pays", em perfeita triangulação das transferências culturais, rastreia a criação, publicação, tradução e circulação da obra Meu Paiz, de autoria do diplomata chinês Chen Jitong, analisando as imagens literárias de seu país em contextos franco-brasileiros para a compreensão da imbricação cultural sino-francesa-brasileira. 


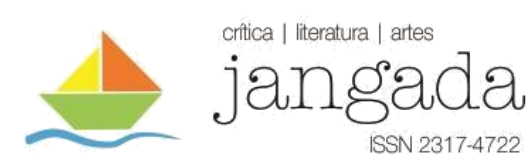

Na próxima sequência, temos dois artigos que discutem a recepção: Ye XU, em "La poésie de Verlaine et la poésie chinoise dans la perspective de la réception", reflete sobre as aproximações da poesia chinesa, nos anos de 1910 a 1930, com a poesia de Paul Verlaine, figura emblemática do poeta maldito, cujos poemas se misturavam às questões da evolução da poesia chinesa, que buscava sua modernização e era sensível à herança da tradição, de modo que Verlaine era visto como um revolucionário por sua liberdade de versificação, haja vista os chineses quererem se desvencilhar de uma prosódia canônica e antiga. Earl Fitz, também às voltas com a recepção em "A recepção da Literatura Brasileira nos Estados Unidos”, reflete sobre sua própria experiência ao longo de anos de ensino e dedicação à pesquisa da "literatura interamericana nos Estados Unidos", oferecendo-nos um panorama da leitura da produção brasileira pelos americanos.

Na terceira sequência, a questão colonial e pós-colonial, ainda que em perspectivas diversas, está presente em três artigos do dossiê. Michel Espagne, em "Alexander von Humboldt et la construction franco-allemande de l'Amérique Latine", volta-se para o escritor, naturalista e explorador alemão francófono, responsável pela preparação dos mais de 30 volumes em francês que compõem as Viagens às regiões equinociais do novo continente, que, segundo o autor, incorpora uma transferência cultural triangular paradigmática. Van Quang Pham, em "La reconfiguration des pensées occidentales au Sud-Vietnam postcolonial”, mostra como os intelectuais vietnamitas, em meio a crises de ordem moral e material, refugiaram-se em reflexões filosóficas, recorrendo às ideias ocidentais como modo de agir e de viver no país. Hans-Jürgen Lüsenbrink, por sua vez, engata uma marcha à ré no tempo e nos leva à época dos conquistadores espanhóis em "Intercultural communication and cultural transfers in the colonial context. The encounter between Pizarro and Atahualpa in 1532 and its discursive representations in early-modern cultures", artigo que aborda a questão das representações históricas do encontro entre o rei dos Incas, Atahualpa, e o conquistador Francisco Pizarro, no século XVI, sob os diferentes discursos produzidos pelos espanhóis que corroboraram para a construção de uma versão oficial do célebre episódio, hoje revisitado por inúmeros historiadores.

Na penúltima sequência do dossiê, apresentamos artigos cujas contribuições, desde o título, expressam o tema da transferência cultural. Ekaterina Dmitrieva, em "Les premisses du transfert culturel dans les sciences humaines russes du XIXe siècle: la contribution de Vladimir Stasov", traz à luz o russo Vladimir Stasov, proeminente crítico de arte e autor de "uma série de estudos, hoje semiesquecidos, nos quais, ao mesmo tempo que defendia a ideia de arte Jangada | ano 9, nr. 17, jan/jun, 2021 | ISSN 2317-4722 
nacional, tentava provar a continuidade da arte russa em relação à arte asiática", algo que suscita questionamentos a respeito da "exigência de identidade" proposta pelo autor. A contribuição de Rubens Vinícius Marinho Pedrosa e Pedro Paulo Garcia Ferreira Catharina, "Naturalismo e transferências culturais: o caso França-Bélgica", trata das trocas artístico-intelectuais entre os escritores Camille Lemonnier e Joris-Karl-Huysmans, destacando como a comunicação entre os dois favoreceu a circulação de ideias e contribuiu para a transferência cultural não só entre editores, mas também a literatura dos dois países, uma vez que Lemonnier era belga e Huysmans francês. Nos três próximos artigos, primeiramente, Anne-Frédérique Schläpfer, em "Le genre national comme transfert culturel”, propõe, sob a noção de transferência cultural, considerar as relações entre a literatura francófona e não francófona, e, para isso, aborda o fenômeno literário sob o crivo da noção de gênero nacional, refletindo sobre como o romance inglês moldou o mundo francófono entre os anos de 1920 até o fim dos anos de 1940. Romuald Valentin Nkouda, por sua vez, em “(Auto)biographies - parallèles et médiation culturelle transnationale: une lecture germano-africaine de la notion de 'transfert culturel'", analisa, a partir do percurso biográfico, a circulação de autores africanos na Alemanha, ressaltando como resultado "diferentes mediações transnacionais e transculturais". Por fim, em "Imprensa periódica franco-americana: conexões, transferência e identidade", Valéria dos Santos Guimarães nos oferece "um panorama da publicação de impressos periódicos francófonos nas Américas do Norte, Central e do Sul nos séculos XIX e XX”, sob a perspectiva das transferências culturais entre a França e diferentes países do continente americano.

A última sequência do dossiê é finalizada com dois artigos que nos apresentam perspectivas sobre a cultura ocidental em relação com outras culturas. Miki Okubo, em "La notion 'gothique' traduite dans la culture pop du Japon contemporain”, trata do movimento 'gothic and Lolita' no Japão, resultado não só da admiração dos japoneses pela cultura ocidental e o infantilismo como traço cultural, mas também por suas imbricações literárias, haja vista o conceito ter sido emprestado do romance do escritor russo, naturalizado americano, Nabokov. E, por fim, Mahamadou Lamine Quedraogo, em "Repenser l'épistémologie des sciences en Afrique: les cultures africaines comme stratégie de mieux-être", traça um panorama do status secundarizado da cultura em Burkina Faso e discute aspectos epistemológicos do desenvolvimento e o fato de a comunidade internacional compreender a África a partir de um repositório de modelos de saber inteiramente ocidentais. O autor sugere a desconstrução desses modelos e propõe "repensar a epistemologia das ciências naturais à luz das culturas africanas para fazer da ciência na África o testemunho do pensamento africano." 
$\mathrm{Na}$ seção varia, trazemos a contribuição de Redha Benmessaoud que em "Glottopolitique(s) et pouvoir(s): textes et contextes" revisita o conceito de glottopolitique, cunhado por Louis Guespin, a partir de períodos específicos da história europeia, demarcando como as línguas foram "subjugadas" por políticas dos poderes totalitários em curso, aqui representados por Mustafa Kemal Atartürk, Stalin, Hitler e Mussolini. Na sequência, Erick Araujo em "Lima Barreto: literatura, música e existências", nos oferece "uma releitura das palavras de Lima Barreto sobre a chamada música popular" ao propor "uma análise das críticas destinada ao autor".

Para concluir este número dedicado às transferências culturais trazemos o texto de François Weigel, comentando a obra recém publicada de Étienne Sauthier, Proust sous les tropiques. Diffusion, réceptions, appropriations et traduction de Marcel Proust au Brésil (1913-1960), trabalho que investiga as múltiplas facetas da recepção de Proust no Brasil, sobretudo entre intelectuais brasileiros, ao mesmo tempo em que figura como exemplo não só da circulação das ideias, mas da transferência cultural enquanto fenômeno capaz de "abraçar" os deslocamentos culturais em sua totalidade.

Para finalizar, a partir dos artigos recolhidos e dos locais de onde escrevem os autores, percebemos que o dossiê reúne uma variedade de lugares, objetos, pontos de vista, pensamentos, linguagens, permitindo observar, em sua diversidade de gêneros e geografias, contextos nacionais e linguísticos, a gama de estudos possíveis e atualmente realizados sobre as transferências culturais.

A todos, uma ótima leitura!

Dirceu Magri - UFV, Brasil Michel Espagne - ENS-CNRS, França

Editores deste número 